\title{
Suppression Application of Copper Oxide \\ Nanoparticles for Wilt-Inducing Fusarium Equiseti in Wheat
}

Tarek Abdelghany ( $\square$ tabdelghany@yahoo.com )

Al-Azhar University https://orcid.org/0000-0001-6418-5890

Asmaa A. Alharbi

2Biology Department, Faculty of Science, Jazan University, Jazan, Saudi Arabia

Aisha M. H. Al-Rajhi

3Biology Department, Faculty of Science, Princess Nourah Bent Abdularahman University

\section{Research}

Keywords: Copper oxide nanoparticles, Fusarium equiseti, wheat, wilt disease

Posted Date: September 17th, 2021

DOl: https://doi.org/10.21203/rs.3.rs-882655/v1

License: (c) (i) This work is licensed under a Creative Commons Attribution 4.0 International License.

Read Full License 


\section{Abstract}

Background: Recently, nanoparticles has proposed as a different and ecofriendly tools for solving many problems in agricultural field.

Aim: The current investigation is an attempt to assess the antifungal activity of Copper oxide nanoparticles (CuONPs) against wheat wilt disease.

Results: Isolates of Fusarium sp., Alternaria sp. and Rhizoctonia sp. species were recovered from wheat roots showed willt symptoms. Highest frequency (77.12\%) was associated to Fusarium sp. Fusarium sp. isolates from pathogenicity test indicated that isolate (F1) out the highest frequency isolates caused high percentage of wilt reached to $65.1 \%$. Molecular identification of F1 isolate was performed using ITS rRNA gene, and confirmed that it belong to $F$. equiseti. Inhibition (\%) of $F$. equiseti growth was 3.45 and $16.66 \%$ at $100 \mathrm{ppm}$, and it was 74.14 and $78.21 \%$ at $400 \mathrm{ppm}$ of CuONPs at 5 and 8 days, respectively. The action mechanism of CuONPs on $F$. equiseti inhibition was elucidated by transmission electron microscopy. CuONPs induced morphological changes and damage of the cell membranes of the $F$. equiseti. Healthy wheat plant without $F$. equiseti infection exhibited 11.24 ug. g- 1 dry weight of total phenol content (TPC), while infected plant showed highest content 14.25 ug. g-1dry weight. CuONPs at 200ppm induced TPC of infected plant by F. equiseti to $16.67 \mathrm{ug} . \mathrm{g}^{-1} \mathrm{dry}$ weight. Increment in Peroxidase, polyphenol oxidase, superoxide dismutase activities in wheat plant cultivated in soil inoculated by $F$. equiseti and amended with $400 \mathrm{ppm}$ of CuONPs were recorded comparatively to wheat plant cultivated in soli inoculated by F. equiseti but without CuONPs.

Conclusion:The inhibitory effects of CuONPs are very actual management strategies for the control wheat wilt disease caused by $F$. equiseti in respective to present and future studies.

\section{Background}

Most of Human beings depend on Wheat (Triticum aestivum L.) as a source of food. Therefore it considered the most vital cereal crop in many countries after rice. Phytopathogenic fungi play a critical role in destroying and reducing wheat yield as well as other plants. Several fungi colonize and invade in the root of wheat plants causing root rots(Bentley et al., 2006). Wheat plant at vegetative growth and other development of growth such as flowering process may infect by various diseases via numerous species of fungi. Therefore many studies mentioned that leaves, stems, basal stem tissues, seedlings, seed and roots of wheat were attacked by a large number of fungi (Wiese, 1987, Moya-Elizondo et al., 2011). A main problems associated with plant cultivation and crops production are fungal diseases particularly Fusarium diseases. Deterioration of significant crops was recorded as a result of Fusarium diseases such as potato dry rot, beans decline, wheat crown rot, wheat head blight, rice bakanae and wheat wilting. According to earlier literature studies, the greatest frequently identified Fusarium spp. related to crown and root rot are F. graminearum, F. culmorum and F. avenaceum (Cook 1980, Kane et 
al.,1987; Specht and Rush1988). Vascular wilt of cumin affected by Fusarium equiseti was reported in 2012 (Suthar and Bhatt 2012).

In numerous fields of Montana, Moya-Elizondo et al., (2011) studied the associated pathogens of wheat. Where $\%$ incidence was $15 \%, 13 \%$ and $8 \%$ for Bipolaris sorokiniana, F. culmorum and $F$. pseudograminearum, respectively. Many reports suggest that the diversity of Fusarium community has dependent on plant rotation (Luque et al., 2005; Wakelin et al., 2008). According to Goswami et al. (2008), tropical and sub-tropical areas are a common habitat of $F$. equiseti. The pathogenicity of $F$. equiseti was recorded on a varied range of plants and it has recorded recently by Hami et al., (2021) as a causal fungus of wilt in chilli wilt in Kashmir valley at Northern Himalayas. Numerous attempts from agronomists to create varieties of wheat resistant to phytpathogens (Harlapur et al., 1993, Ahmed et al., 2009) but theses varieties not continue for long time and become sensitive to most diseases. Therefore the research for novel agent for controlling fungal diseases are necessary to solve these problem.

Currently, the nanoformulations attracted the scientific researchers for its applications in many fields as well as agricultural field not only for controlling the occurrence diseases but also for enhancing the physiological behavior in plants, productivity of crops and development of vegetative growth (Adamovskaya et al., 2005; Servin et al., 2015; Lopez-Lima et al., 2021). Numerous studied the lowest toxicity of metals such as silver, copper, zinc, and iron in nanoforms compared with its salts (Abdel Ghany et al., 2018), nanoparticles of copper, Zinc and iron are 7,30 and 40 times less poisonous as compared to their corresponding sulfate salts of copper (Panyuta et al., 2016).

Copper nanoparticles (CuNPs) was investigated as a fungicide against four phytopathogens by Kanhed et al. (2014), who found that CuNPs inhibit the mycelia development of F. oxysporum, Alternaria alternata, Curvularia lunata and Phoma destructive. Large surface area to volume ratio considered a promising and critical factor for efficacy the suppressing action of CuNPs (Abdel Ghany et al., 2018). Copper oxide nanoparticles (CuONPs) also were applied without any physiological toxicity for suppressed gray mold disease caused by Botrytis cinerea (Elmer and White 2016). Elmer et al. (2018) recorded less disease caused by F. oxysporum and Verticillium dahliae in Tomato and eggplant treated by CuONPs. The studies of Fusarium wilt of numerous plants are well advanced in some regions of the world, but are still narrow elsewhere in wheat. Therefore, the current research focused on controlling the causative agent of wheat wilt by CuONPs with studying the their effects on ultrastructure of pathogen and some biochemical changes in wheat plant.

\section{Methods}

\section{Isolation and identification of wheat wilt accompanying fungi}

Wheat (Triticum aestvium L.; cultivar Giza 171) plants showing symptoms of wilt (Fig. 1) were selected from Six different fields in Menofia Governorate, Egypt. The roots of plant were surface sterilized for 5 
min in $0.1 \%$ sodium hypochlorite, then washed by triple sterile distilled water and dried in air in a laminar flow bench. A root was aseptically chopped transversely and longitudinally into $1 \mathrm{~cm}$, then the segments were placed on potato dextrose agar (PDA) in petri plates supplemented with $0.4 \%$ streptomycin sulfate for inhibiting the bacterial growth, followed by incubation for 6 days at $25^{\circ} \mathrm{C}$. The developed fungal colonies were purified via a hyphal tip technique (Dhingra and Sinclair 1985) and then identified according to mentioned identification keys including macro- and micro-scopic examination including observation of growth rate, colony color, presence or absence of macroconidia, microconidia, chlamydospores (Nelson et al 1983; Barnett and Hunter 1986; 2006, Leslie and Summerell, 2006). The purified isolates were kept on slants containing PDA and preserved in refrigerator for further tests.

\section{Pathogenicity test}

Conidial suspensions of three fungal isolates belonging to Fusarium sp. (F1, F2 and F3) were used as inoculums for soil cultivated by wheat plants. Spores suspension was centrifuged at $3000 \mathrm{rpm}$ per $5 \mathrm{~min}$, then the spores pellet was washed, followed by repeating centrifugation. The source of used wheat grains (Triticum aestvium L.; cultivar Giza 171) was Agricultural Research Center, Giza, Egypt. The wheat grains were surface sterilized by $\mathrm{HgCl}_{2}(0.1 \%)$, followed by rinsing with distilled water. The grains were cultivated in $20 \mathrm{~cm}$ diameters Plastic pots filled with $2 \mathrm{~kg}$ of autoclaved soil/ pot, then the soil in pots inoculated at level $2 \times 10^{4}$ spores $/ \mathrm{ml}(200 \mathrm{ml})$ suspensions that calculate using a hemocytometer. The pots were irrigated each 5 days and the developed seedlings were viewed and disease assessment was documented through 25 days (Alon et al., 1973). The causative agent of wilting disease of wheat from F1, F2 and F3 that confirmed by pathogenicity test was used for further study.

$$
\text { Pathogenicity }=\frac{\text { Numberofwiltingplants }}{\text { Totalnumberofplants }} \times 100
$$

(1)

\section{Molecular identification of pathogen}

From pathogenicity test, the potent isolate of Fusarium sp. was inoculated on plate containing PDA plates, followed by incubation at $25^{\circ} \mathrm{C}$ for 5 days for molecular identification (Hami et al., 2021). DNA was extracted from mycelia growth using Microprep Kit of quick-DNA fungi/bacteria (Zymo research; D6007) via the manufacturer's protocol of Sigma Scientific Services Company, Egypt. PCR was achieved via Maxima Hot Start PCR Master Mix (Thermo; K1051). ITS1-F (5'- TCCGTAGGTGAACCTGCGG-3') and ITS4-R (5'- TCCTCCGCTTATTGATATGC-3') were used as forward and reverse primers, respectively for the amplifcation of pathogen DNA. Thermal Cycler Condition: One cycle for initial denaturation $94^{\circ} \mathrm{C}$ for 6 min., 35 cycles of denaturation, annealing and Extension for 45,45 and $60 \mathrm{~s}$ at 94,56 and $72^{\circ} \mathrm{C}$, respectively. One cycle for final extension for $5 \mathrm{~min}$ at $72^{\circ} \mathrm{C}$. Pathogen DNA was examined using gel electrophoresis. BLAST analysis was applied for sequences homologous sequences at NCBI (http://ncbi.nlm.nih. gov/BLAST). Neighbor joining method was used for reconstruction the evolutionary tree. 


\section{Copper oxide nanoparticles}

Copper oxide nanoparticles (CuONPs) less than $100 \mathrm{~nm}$ were provided in powder form from Nawah Scientific company, Egypt .

\section{Antifungal activity assessment of CuONPs on radial growth and ultra-structures of pathogen}

Potato dextrose agar (PDA) medium supplemented with different concentrations of CuONPs $(100,200$, $400 \mathrm{ppm}$ ) was applied for deterring the inhibitory action of CuONPs against pathogen (Abdel Ghany et al. 2020). Disc $(0.5 \mathrm{~mm})$ of actively growing colony of pathogen at 5 days incubation period was inoculated in the center of plat containing growth medium, incubated at $25^{\circ} \mathrm{C}$ for 7 days, followed by measuring the colony radius and recording the inhibition \% according to the following equation.

$$
\text { Inhibition\% }=\frac{(\mathbf{R G C}-\mathbf{R G T})}{\mathbf{R G C}} \times 100(2)
$$

Where RGC, radial growth of the control and RGT, radial growth of treatment. Medium without any concentration of was used as control.

Transmission electron microscope (TEM) studies were carried out as following (Abdel Ghany and Tayel 2009), fungal pathogen was inoculated on cellophane membrane located on CYA petri dish amended with different concentrations of CuONPs. Tips of fungal hypha were cuted under the light microscope from the margin of colony, then fixed in $5 \%$ gluteraldehyde for $24 \mathrm{~h}$. followed by washing using phosphate buffer ( $\mathrm{pH} 7.2)$ for three times. The buffer was removed, then the sections were dipped for $2 \mathrm{~h}$ in aqueous solution of $1 \%$ osmium tetraoxide. Osmium solution was removed from hyphae sections, then it dehydrated using a series of different doses of ethanol (50-96\%). After removing the absolute ethanol, propylene oxide was added to the hyphae sections for $60 \mathrm{~min}$. The hyphae sections were placed in propylene oxide and Epon 812 resin (2:1), followed by placed in pure resin for $12 \mathrm{~h}$, then placed at $60^{\circ} \mathrm{C}$ in an oven for $48 \mathrm{~h}$. Using ultra microtome, blocks $(50 \mathrm{~nm})$ were sectioned, then stained using uranyl acetatelead citrate 500A and examined by TEM (C Joel Jem- 1200 EX II. Acc. Voltage 120 KV. MAG- medium) at the Regional Center for Mycology and Biotechnology, Al-Azhar University, Cairo, Egypt.

\section{Pot experiment and effect of CuONPs on plant pathogenic fungus}

From the pathogenicity test, the identified isolate of pathogen was re-subcultured on the autoclaved PD broth medium under aseptic conditions, then incubated for 7 days at $25^{\circ} \mathrm{C}$. After incubation period, the fungus spores were taken in for spores suspensions preparation in sterile water and used for inoculation of plants at level $2 \times 10^{4}$ spores $/ \mathrm{ml}$ suspensions that calculate using a hemocytometer. The source of used wheat grains (Triticum aestvium L.; Cultivar Giza 171) was Agricultural Research Center, Giza, Egypt. The wheat grains were surface sterilized by $\mathrm{HgCl}_{2}(0.1 \%)$, followed by rinsing with distilled water. The 
grains were cultivated in $20 \mathrm{~cm}$ diameters Plastic pots filled with $2 \mathrm{~kg}$ of autoclaved soil/ pot and then divided into groups for treatments as following, without inoculation, inoculated with phytopathogen, inoculated with phytopathogen $+100 \mathrm{ppm}$ CuONPs, inoculated with phytopathogen $+200 \mathrm{ppm}$ CuONPs, inoculated with phytopathogen $+400 \mathrm{ppm}$ CuONPs, without inoculation $+100 \mathrm{ppm}$ CuONPs, without inoculation $+200 \mathrm{ppm}$ CuONPs and without inoculation $+400 \mathrm{ppm}$ CuONPs. The number of grains in each pot was 6 in triplicate, irrigated with sterilized water each 5 days, incubated for 20 days at approximately $24 \pm 2^{\circ} \mathrm{C}$ under natural photoperiod under greenhouse conditions. During seedling growth, the symptoms of wilting disease were observed, and the plants were collected for biochemical analysis and further study (Abdel Ghany et al., 2015).

\section{Total phenolic content determination in shoot extracts of wheat plants}

According to Kaur and Kapoor (2002), total phenolic content in shoot extract of wheat plants was determined. The reaction mixture for $5 \mathrm{~min}$ contained $0.5 \mathrm{ml}$ of wheat plant extract, $2.5 \mathrm{ml}$ distilled water and $0.25 \mathrm{ml}$ of $2 \mathrm{~N}$ Folin-Ciocalteu reagent. Followed by the addition of $0.75 \mathrm{ml}$ of $\mathrm{Na}_{2} \mathrm{CO}_{3}(20 \% \mathrm{w} / \mathrm{v})$ beside $0.95 \mathrm{ml}$ distilled water. Then the reaction mixture was kept at $37^{\circ} \mathrm{C}$ in without exposure to light for $1 \mathrm{~h}$. At $765 \mathrm{~nm}$, the absorbance was recorded to determine total phenolic content compared to Gallic (GA) acid as standard and expressed as mg GA g-1 dry weight.

\section{Antioxidant activity}

The treated plant seedlings were collected for measuring the antioxidant activity using $5 \mathrm{~g}$ of fresh leaves and stems via homogenization in cold phosphate buffer $(0.05 \mathrm{M}$, with $\mathrm{pH} 6.5)$. The homogenized extract was centrifuged for $10 \mathrm{~min}$ at $4000 \mathrm{~g}$. The obtained supernatant was applied as a source enzymes after rising to $5 \mathrm{ml}$. The formed precipitate from centrifugation process was washed with distilled water, then re centrifuged, the collected residues were immersed for 60 min in10 $\mathrm{ml} \mathrm{NaCl}(1 \mathrm{M})$ to release cell wallbound peroxidase (POX), followed by centrifugation for $10 \mathrm{~min}$ at $4000 \mathrm{~g}$. The obtained supernatant was applied as a source of wall-bound POX (Saroop et al. 2002). According to Beyer and Fridovich (1987), nitro blue tetrazolium (NBT) reduction method was used superoxide dismutase (SOD) activity, while soluble and cell wall-bound (POX) and polyphenol oxidase (PPO) were determined according to Saroop et al. (2002) and Kar and Mishra (1976) respectively. $\mathrm{U} \mathrm{mg}^{-1}$ protein $\mathrm{min}^{-1}$ was applied for expression of enzymes activity.

\section{Statistical analysis}

With using SPSS software (version 14), all results were analyzed and it was expressed as mean \pm SD.

\section{Results}

\section{Isolation and pathogenicity}


Fungal isolates belonging to Fusarium sp., Alternaria sp., Rhizoctonia sp. were isolated from wilted wheat plants (Fig. 2). Fusarium sp. showed the highest frequency (77.12\%) followed by Alternaria sp. (15.84\%), followed Rhizoctonia sp. (7.04\%). Pathogenicity test was performed using three the highest frequency isolates of Fusarium sp.( Fig. 3). The highest percentage of wilt was recorded by isolates F1 (65.1\%) followed by isolates F2(30.5\%) and F3 (22.4\%). For confirmed, the pathogenicity of isolates F1, it was reisolated from diseased wheat plants that artificially inoculated with pathogen.

The morphological identification of grown pathogen (Fig. 4) from pathogenicity test was confirmed using molecular characterization, which is based on ITS rDNA (Figs. 5A and B). Multiple sequence alignment on a database (BLAST) was used for studying the 18S rRNA sequence of the $F$. equiseti isolate. Result of alignment profile(Fig. 5B) demonstrated that $F$. equiseti strain SKASS_BRH16F1 rRNA amplicon closely exhibited harmonized to other isolates of $F$. equiseti (>99\%) as shown in phylogenetic tree(Fig. 5A).

\section{Inhibition Of Pathogen By Cuonps}

Colony diameter of F. equiseti was determined at the incubation periods of 5 days and 8 days at different concentrations of CuNPs. Results in table (1) exhibited increase in fungus diameter at low concentration of CuONPs as the incubation period increased but negligible increase in colony diameter was observed at high concentration of CuONPs particularly at $400 \mathrm{ppm}$. Therefore the inhibition (\%) of fungal growth at 5 and 8 days was 3.45 and $16.66 \%$ at 100 ppm while it was 74.14 and $78.21 \%$ at 400 ppm, respectively. At the same time Sporulation (\%) was accompanied to inhibition \%. In contrast, the growth at control still grew clearly and their diameter increased normally.

TEM examination showed that $F$. equiseti generally displayed integrity of the internal organs including cell membrane, mitochondria, organized cytoplasm, and visible nuclei and with well-defined envelopes as well as cell wall (Fig. 5). On the other hand, ultrastructures in treated fungus with CuONPs reflected the presence of distortions inside fungal mycelia as well as conidia (Fig. 5), these alterations increment with the increasing CuONPs concentration. The Plasma membrane remained intact at $100 \mathrm{ppm}$ of CuONPs but become more affected at $200 \mathrm{ppm}$ of CuONPs. Clear collapsing in cell membrane out from cell wall with irregular shape was observed particularly at 200 and 400 ppm of CuONPs, and the cell approximately appeared empty (Fig. 5). Raised condensation and aggregation of cytoplasmic characterize the fungus cell exposed to CuONPs.

Total phenol content of wheat plant infected by F. equiseti was highest14.25 ug. $\mathrm{g}^{-1}$ dry weight than that detected in healthy plant without infection 11.24 ug. $\mathrm{g}^{-1}$ dry (Table 2). Negligible variation in the total phenol content was observed with the addition of CuONPs to plant without infection, while its addition with F. equiseti increased the total phenol content to $16.67 \mathrm{ug} \cdot \mathrm{g}^{-1}$ dry weight at $200 \mathrm{ppm}$ of CuONPs (Table 2). 
Table 1

The Colony diameter, Inhibition and Sporulation of Fusarium sp. according to incubation period at various CuONPs concentrations.

\begin{tabular}{|lllllll|}
\hline CuONPs Concentration (ppm) & \multicolumn{2}{l}{ Growth (cm) } & \multicolumn{2}{l|}{ Inhibition (\%) } & \multicolumn{2}{l|}{ Sporulation (\%) } \\
\cline { 2 - 7 } & $\mathbf{5}$ days & $\mathbf{8}$ days & $\mathbf{5}$ days & $\mathbf{8}$ days & $\mathbf{5}$ days & $\mathbf{8}$ days \\
\hline Control & $5.8 \pm 0.52$ & $7.8 \pm 0.33$ & 0.0 & 0.0 & 100 & 100 \\
\hline 100 & $5.6 \pm 0.45$ & $6.5 \pm 0.25$ & 3.45 & 16.66 & 95 & 97 \\
\hline 200 & $3.4 \pm 0.06$ & $3.8 \pm 0.66$ & 41.38 & 51.28 & 60 & 65 \\
\hline 400 & $1.5 \pm 0.25$ & $1.7 \pm 0.15$ & 74.14 & 78.21 & 22 & 23 \\
\hline Chemical fungicide & $1.1 \pm 0.02$ & $1.3 \pm 0.22$ & 81.03 & 83.33 & 15 & 16 \\
\hline
\end{tabular}

Table 2

Total phenol content of wheat plant cultivated in soil inoculated by F. equiseti and amended by CuONPs

\begin{tabular}{|l|l|}
\hline Treatment & *Total phenol (ug. $\mathbf{g}^{-1}$ dry weight) \\
\hline Control & $11.24 \pm 0.7$ \\
$100 \mathrm{ppm}$ & $10.55 \pm 0.5$ \\
$200 \mathrm{ppm}$ & $11.12 \pm 0.4$ \\
\hline $400 \mathrm{ppm}$ & $11.55 \pm 0.5$ \\
\hline F. equiseti & $14.25 \pm 1.2$ \\
\hline F. equiseti $+100 \mathrm{ppm}$ & $16.48 \pm 1.5$ \\
\hline F. equiseti $+200 \mathrm{ppm}$ & $16.67 \pm 0.4$ \\
\hline F. equiseti $+400 \mathrm{ppm}$ & $13.08 \pm 0.8$ \\
\hline
\end{tabular}

\section{Antioxidant Enzymes}

In the current results, activities of superoxide dismutase (SOD), polyphenol oxidase (PPO)and Cell wall bound peroxidase (POX) increased in plant infected by pathogen (Table 3). Remarkable activities of oxidative enzymes were observed with the addition of CuONPs to soil inoculated by pathogen particularly at high concentration $400 \mathrm{ppm}$. Therefore, these enzymes protect the plant from the biological and nonbiological stresses resulted from the influence of pathogen and metal, respectively. 
Table 3

Antioxidant activity of wheat plant infected by F. equiseti and treated by CuONPs

\begin{tabular}{|llll|}
\hline \multirow{2}{*}{ Treatment } & \multicolumn{2}{l}{ Antioxidant activity } & \\
\cline { 2 - 4 } & SOD & PPO & Cell wall bound POX $\left(\mathbf{U ~ m g}^{-1}\right.$ protein min- $)$ \\
\hline Control & $11.25 \pm 1.0$ & $13.78 \pm 0.5$ & $0.87 \pm 0.01$ \\
\hline $100 \mathrm{ppm}$ & $11.74 \pm 0.8$ & $13.91 \pm 0.4$ & $0.92 \pm 0.02$ \\
\hline $200 \mathrm{ppm}$ & $11.89 \pm 1.2$ & $13.79 \pm 1.5$ & $1.62 \pm 0.01$ \\
\hline $400 \mathrm{ppm}$ & $12.61 \pm 1.3$ & $13.85 \pm 1.2$ & $1.81 \pm 0.05$ \\
\hline F. equiseti & $12.56 \pm 0.6$ & $15.56 \pm 1.4$ & $1.98 \pm 0.04$ \\
\hline F. equiseti $+100 \mathrm{ppm}$ & $13.54 \pm 0.5$ & $16.04 \pm 1.1$ & $2.50 \pm 0.01$ \\
\hline F. equiseti $+200 \mathrm{ppm}$ & $14.25 \pm 0.4$ & $16.72 \pm 0.4$ & $2.79 \pm 0.02$ \\
\hline F. equiseti $+400 \mathrm{ppm}$ & $21.41 \pm 1.2$ & $26.41 \pm 1.8$ & $10.2 \pm 0.06$ \\
\hline
\end{tabular}

\section{Discussion}

The observed symptoms of wheat wilting disease initiate with partial yellowing of leaves, followed by complete yellowing of plant, during the growth of seedlings. The ability of fungal isolates from wilted seedlings to cause wilt symptoms was varied the percentage of infection and disease severity. Theses observation may related to isolate pathogenicity. The results of pathogenicity test confirmed that $F$. equiseti considered the causative agents of wheat will disease. Therefore, the identification was documented by molecular tool. According to some studies (Romanelli et al. 2010; Delgado-Serrano et al. 2016), ITS rDNA application for fungi identification at level of species is mainly depend on the variable nature of the ITS areas of DNA. In Nigeria, Chimbekujwo (2020) studied the wilt disease of cotton (Gossypium hirsutum), who found that the major (90\%) isolated fungi belong to Fusarium solaniand $F$. equiseti, these study documented that $F$. equiseti isolates were less virulent compared to $F$. solani. Some studies focused on the pathogenicity of $F$. equiseti, where numerous members of the leguminoseae beside some cereals were reported as a host range for $F$. equiseti causing root rot and damping-off diseases (Rubella et al., 2008). In Algeria „Bencheikh et al. (2020) documented recently the first report on crown rot and damping-off on durum wheat caused by Fusarium equiseti. In China, the first report on cauliflower wilt by F. equiseti was mentioned previously in 2017 (Pan-Liang et al. 2017). Inhibition \% of $F$. equiseti growth was promoted by high concentrations of CuONPs 200 and $400 \mathrm{ppm}$. It can be noted that the fungicidal potential of CuONPs depends on its concentrations as well as on fungal species as mentioned previously (Pariona et al., 2019). The inhibitory effect of CuONPs could be attributed to smallest nanoparticles size. The applied of CuONPs as fungicide was documented against many species of Fusarium including F. oxysporum, F. equiseti and F. culmorum which are the most common phytopathogens in Central India according to Bramhanwade et al. (2015). Inhibition of $F$. equiseti growth 
at different concentrations of CuONPs at 5th and 8th days was recorded. Viet et al. (2016) observed that Fusarium sp. was not increased with increasing incubation period from 3 to 9 days at 450 ppm CuNPs. Toxicity of CuONPs in the current study may depends on the combination of numerous factors like as concentration and length of exposure.

TEM revealed the presence of many alterations in F. equiseti cells and spores exposed to CuONPs. Surprisingly, plasma membrane ruptured at 400 ppm of CuONPs. Abdel Ghany et al. (2020) studied the effect of different levels of CuONPs on the ultrastructure of Aspergillus niger, who revealed that CuNPs treatments stimulated the ultrastructures changes of the fungus. Highly changes were observed in the mycelium and cell membranes of many fungi including Fusarium oxysporum, F. solani, and Neofusicoccum sp.as a result of exposition to CuONPs (Pariona et al., 2019).

Synthesis of phenolic compounds was induced as a result of fungal infection. Cell wall degrading enzymes play a critical role during pathogenesis caused by fungi, therefore as mentioned previously, phenolic compounds suppressed the action of cell wall degrading enzymes produced by F. oxysporum (Modafar and Boustani, 2001). Recently, El-Sharkawy and El-Shora (2020) observed decreasing in pectinase, proteases, xylanase and cellulase activities by plant phenolic compounds. Addition of CuONPs at 200ppm increased the total phenol content of the infected wheat plant to $16.67 \mathrm{ug} \cdot \mathrm{g}^{-1} \mathrm{dry}$ weight by $F$. equiseti. Plants possess numerous defense mechanisms against invasion of phytopathogens and play a critical role in plants cultivated under stress conditions. According to the physiological studies, enzymatic and non-enzymatic mechanisms were reported as a protectors to repress the progress the pathogen. Certain enzymes POX, PPO, and SOD recognized as antioxidant enzymes, and protect the plants through peroxidation prevention of membrane lipid and minimize oxidative stress resulting from pathogenicity. A defense reaction to the cellular injury caused by phytopathogen toxins was reported previously (Chandrakar et al. 2018) via stimulation of the antioxidant system in plant. The present study showed that high concentration of CuONPs (400 ppm) inhibit the growth of pathogen in vitro compartment to low concentration, however oxidative enzymes increased in plant infected by pathogen and treated with high concentration $400 \mathrm{ppm}$ of CuONPs (Table 3). These observation confirmed that the essential role of antioxidant system against non-biostress condition. Choudhary et al. (2017) in another study evaluated the defense mechanism in maize plant infected by Curvularia leaf spot. Who recorded that SOD and PPO activities were significantly increased in plant treated by Cu-chitosan NPs. Degeneration and scavenging of reactive oxygen species may be due to oxidative enzymes activities that increased after CuONPs treatments. These processes protect the plant from oxidative stress throughout pathogen attack.

\section{Conclusion}

The effect of CuONPs on $F$. equiseti as a causative agent of wheat wilt was investigated in vitro and under greenhouse conditions. CuONPs treatments are very effective management strategies for the control of $F$. equiseti in respective to present and future studies. In pot experiment, CuONPs had an fungicide effect on $F$. equiseti and minimize the wilt infection in the seedlings of wheat. Addition of 
CuONPs to inoculated soil by $F$. equiseti increased the defense mechanism represented by oxidative enzymes of wheat plant against pathogen.

\section{Abbreviations}

CuONPs

Copper oxide nanoparticles

CuNPs

Copper nanoparticles

NPs

Nanoparticles

SOD

Superoxide dismutase

PPO

Polyphenol oxidase

POX

Cell wall bound peroxidase

RGC

Radial growth of the control

RGT

Radial growth of treatment

PDA

Potato dextrose agar

TEM

Transmission electron microscope

\section{Declarations}

Ethics approval and consent to participate

Not applicable

Consent for publication

Not applicable

Availability of data and material

All data generated or analyzed during this study are included in this published article.

Competing interests

The authors declare that they have no conflict of interest. 
Funding

This research did not receive any specific grant from funding agencies in the public, commercial, or notfor-profit sectors.

Authors' contributions

All authors have read and approved the manuscript

ATM: Designed, Performed some experiments; Analyzed and interpreted the data; Wrote the paper.

AAA: Designed some experiments; Analyzed and interpreted the data

AMHA: Conceived and designed the experiments; Analyzed and interpreted the data; Wrote the paper.

Acknowledgements

Al-Azhar University, Jazan university and Princess Nourah Bent Abdularahman University

\section{References}

1. Abdel Ghany, T.M., Aisha, M., Al-Rajhi, H., Al Abboud, M.A., Alawlaqi, M.M., Magdah, G., Helmy, E.A.M., Mabrouk, A.S. (2018) Recent advances in green synthesis of silver nanoparticles and their applications: about future directions: a review. Bio Nano Sci 8(1), 5-16

2. Abdel Ghany, T. M., Bakri, M. M., Al-Rajhi, A. M. H., Al Abboud, M. A., Alawlaqi, M. M., and Shater, A. R. M. (2020). "Impact of copper and its nanoparticles on growth, ultrastructure, and laccase production of Aspergillus niger using corn cobs wastes," BioRes. 15(2), 3289-3306. DOI:

10.15376/biores. 15.2.3289-3306

3. Abdel Ghany, T.M. and Tayel AA. 2009 Efficacy of Certain Agrochemicals Application at Field Rates on Soil Fungi and Their Ultrastructures. Research Journal of Agriculture and Biological Sciences, 5(2): $150-160$

4. Abdel Ghany TM, Masrahi YS, Mohamed A, Abboud A, Alawlaqi MM, and Nadeem I Elhussieny (2015) Maize (Zea Mays L.) Growth and Metabolic Dynamics with Plant Growth-Promoting Rhizobacteria under Salt Stresses. J Plant Pathol Microb 6: 305. doi:10.4172/2157-7471.1000305

5. Adamovskaya VG, Linchevskiy AA, Molodchenkova OO, Tsiselskaya LI. Lectins of the cell walls of barley seedlings at Fusarium culmorum infection and influence of salicylic acid. Physiol Biochem Cultivated Plants. 2005;3:267-274.

6. Ahmed, M.U., K. Abul and I.H. Mian. 2009. Screening of wheat germplasm for their susceptibility against different seedling diseases. Bangladesh J. Agril. Res., 34(4): 673-681.

7. Alon, H., Katan, J. and Kedar, N. 1973. Factors affecting penetrance of resistance to Fusarium oxysporum f.sp. Lycopersici in tomatoes. Phytopathology, 64: 455- 461. 
8. Bencheikh A, Rouag N, Mamache W and Belabed I (2020) First report of Fusariumequiseti causing crown rot and damping-off on durum wheat in Algeria. Archives of Phytopathology and Plant Protection, DOI: 10.1080/03235408.2020.1804303

9. Barnett, H.L. and Hunter, B.B. 1986. Illustrated Genera of Imperfect Fungi 4th Ed., Macmillan Publishing Co., New York. 218 p.

10. Bentley, A.R., M.G. Cromey, R. Farrokhi-Nejad, J.F. Leslie, B.A. Summerell and L.W. Burgess. 2006. Fusarium crown and root rot pathogens associated with wheat and grass stem bases on the South Island of New Zealand. Australasian Plant Pathol. 35(5): 495-502

11. Beyer JR, Fridovich WF (1987). Assaying for superoxide dismutase activity: Some large consequences of minor changes in conditions. Anal Biochem 161: 559- 566.

12. Bramhanwade K, Shende S, Bonde S, Gade A, Rai M 2015.Fungicidal activity of Cu nanoparticles against Fusarium causing crop diseases. Environ Chem Lett.14,2 DOI 10.1007/s10311-015-0543-1

13. Chandrakar V, Dubey A, Keshavkant S (2018) Modulation of arsenic-induced oxidative stress and protein metabolism by diphenyleneiodonium, 24- epibrassinolide and proline in Glycine max L. Acta Bot Croat 77:51-61

14. Chimbekujwo I. B. 2020 Frequency and pathogenicity of fusarium wilts (Fusarium solani and Fusarium equiseti) of cotton (Gossypium hirsutum) in Adamawa in Nigeria. Rev. biol. trop vol.48 n.1 San José

15. Choudhary RC, Kumaraswamy R. V., Kumari S, Sharma S. S., Pal A, Raliya R, Biswas P and Saharan V 2017. Cu-chitosan nanoparticle boost defense responses and plant growth in maize (Zea mays L.). Scientific Reports,7: 9754. DOI:10.1038/s41598-017-08571-0

16. Cook, R. J.(1980): Fusarium foot rot of wheat and its control in the Pacific Northwest. Plant Dis. 64, 10611066.

17. Delgado-Serrano, L., Restrepo, S., Bustos, J. R., Zambrano, M. M., and Anzola, J. M. (2016). Mycofier: A new machine learning-based classifier for fungal ITS sequences," BMC Research Notes 9, 402. DOI: 10.1186/s13104-016-2203-3

18. Dhingra, O.D. and Sinclair, J.B. 1985. Basic Plant Pathology Methods CRC, Boca Raton, Florida, USA $355 p$.

19. Elmer W H., Torre-Roche RD, Pagano L, Majumdar S, Zuverza-Mena N, Dimkpa C, Gardea-Torresdey J, and White JC. 2018. Effect of Metalloid and Metal Oxide Nanoparticles on Fusarium Wilt of Watermelon. Plant disease 102,7 ,1394-1401. https://doi.org/10.1094/PDIS-10-17-1621-RE

20. Elmer, W. H., and White, JC. 2016. The use of metallic oxide nanoparticles to enhance growth of tomatoes and eggplants in disease infested soil or soilless medium. Environ. Sci. Nano $12 \mathrm{~W}$. H. Elmer and J. C. White, Environ. Sci.: Nano, 2016, 3, 1072-1079.

21. El-Sharkawy RM, El-Shora HM. 2020 Biocontrol of Wilt-Inducing Fusarium oxysporum by Aqueous Leaf Extract from Egyptian Ammi majus and Ammi visnaga. Egypt. J. Bot. Vol. 60, No.2 pp. 423-435

22. Goswami, R. S., Dong, Y. \& Punja, Z. K. (2008). Host range and mycotoxin production by Fusarium equiseti isolates originating from ginseng felds1. Can. J. Plant Path. 30(1), 155-160 
23. Harlapur, S.I., S. Kulkarni., R.K. Hegde, V.B. Nargund and S. Kulkarni. 1993. Wheat genotypes against foot rot. Curr. Res., Uni. Agricul. Sci, Bang., 22(2): 33-34.

24. Hami , Rovidha S. Rasool , Nisar A. Khan, Sheikh M , Mudasir A. Mir, Nazeer A, Khalid Z. Masoodi. 2021. Morpho-molecular identification and first report of Fusarium equiseti in causing chilli wilt from Kashmir (Northern Himalayas) Ammarah . Scientific Reports 11:3610. https://doi.org/10.1038/s41598-021-82854-5

25. Kane, R. T., R. W. Smiley, M. E. Sorrells(1987): Relative pathogenicity of selected Fusariumspecies and Microdochium bolleyi to winter wheat in New York. Plant Dis. 71, 177181.

26. Kanhed, P., Birla, S., Gaikwad, S., Gade, A., Seabra, A.B., Rubilar, O., Duran, N. and Rai, M. (2014) In Vitro antifungal efficacy of copper nanoparticles against selected crop pathogenic fungi. Materials Letters, 115, 13-17.

27. Kar M, Mishra D (1976) Catalase, peroxidase and polyphenol oxidase activities during rice leaf senescence. Plant Physiol 57:315-319

28. Kaur, C., Kapoor, H.C. (2002) Antioxidant activity and total phenolic content of some Asian vegetables. International Journal of Food Science and Technology, 37, 178-182.

29. Leslie, J.F., Summerell, B.A. 2006. The Fusarium Laboratory Manual, Blackwell Publishing. 193 pages.

30. Lopez-Lima D, Mtz-Enriquez Al, Carrión G, Basurto-Cereceda S, Pariona N. 2021. The bifunctional role of copper nanoparticles in tomato: Effective treatment for Fusarium wilt and plant growth promoter. Scientia Horticulturae, 277, 109810. https://doi.org/10.1016/j.scienta.2020.109810

31. Luque AG, Pioli R, Tonel B, Álvarez DP, 2005. Cellulolytic fungi populations in stubble and soil as affected by agricultural management practices. Biol Agr Hortic 23: 21-142.

32. Modafar, C.E., Boustani, E.E. (2001) Cell wall bound phenolic acid and lignin contents in date palm as related to its resistance to Fusarium oxysporum. Biologia Plantarum, 44, 125-130.

33. Moya-Elizondo, E. A., Rew, L. J., Jacobsen, B. J., Hogg, A. C., and Dyer, A. T. 2011. Distribution and prevalence of Fusarium crown rot and common root rot pathogens of wheat in Montana. Plant Dis. 95:1099-1108.

34. Nelson, P.E., Toussoun, T.A., MARASAS, W.F.O. 1983. Fusarium species. An illustrated manual for identification. Pennsylvania State University Press, University Park, PA. 203 pages

35. Pan-Liang L., Yan-Xia Shi, Meng-Yan Guo, Xue-Wen Xie, A-Li Chai \& Bao-Ju Li (2017) Fusarium wilt of cauliflower caused by Fusarium equiseti in China, Canadian Journal of Plant Pathology, 39:1, 7782, DOI: 10.1080/07060661.2017.1301998

36. Panyuta O, Belava V, Fomaidi S, Kalinichenko O, Volkogon M, Taran N. 2016 The Effect of Pre-sowing Seed Treatment with Metal Nanoparticles on the Formation of the Defensive Reaction of Wheat Seedlings Infected with the Eyespot Causal Agent. Nanoscale Res Lett. 11(1):92. doi: 10.1186/s11671-016-1305-0.

37. Pariona, N., Mtz-Enriquez, A., Sánchez-Rangel, D., Carrión, G., Paraguay-Delgado, F., and Rosas-Saito, G. (2019). Green-synthesized copper nanoparticles as a potential antifungal against plant 
pathogens," RSC Adv. 9(33), 18835-18843. DOI: 10.1039/c9ra03110cRomanelli, A. M., Sutton, D. A., Thompson, E. H., Rinaldi, M. G., and Wickes, B. L. (2010). "Sequence-based identification of filamentous basidiomycetous fungi from clinical specimens: A cautionary note," J. Clin. Microbiol. 48(3), 741-752. DOI: 10.1128/JCM.01948-09

38. Rubella S. Goswami, Yanhong Dong and Zamir K. Punja (2008) Host range and mycotoxin production by Fusarium equiseti isolates originating from ginseng fields ${ }_{1}$, Canadian Journal of Plant Pathology, 30:1, 155-160, DOI: 10.1080/07060660809507506

39. Saroop S, Chanda SV, Singh YD (2002) Changes in soluble and ionically bound peroxidase activities during Brassica juncea seed development. Bulg J Plant Physiol 28:26 -34

40. Servin A., Elmer W., Mukherjee A., Torre-Roche R., Hamdi H., White J. C., Bindraban P.and Dimkpa C., J. Nanopart. Res., 2015, 17, 92.

41. Specht, L. P. \& C. M. Rush(1988): Fungi associated with root and foot rot of winter wheat and populations of Cochliobolus sativus in the Texas Panhandle. Plant Dis. 72, 959963.

42. Suthar, R. S. and Bhatt, P. N., First report of Fusarium equiseti causing vascular wilt of cumin in India. Plant Disease, 2012;96 (12) 1821., https://doi.org/10.1094/PDIS-03-12-0236-PDN

43. Viet PV, Hai Thi Nguyen, Thi Minh Cao, and Le Van Hieu 2016. Fusarium Antifungal Activities of Copper Nanoparticles Synthesized by a Chemical Reduction Method. Journal of Nanomaterials Volume 2016, Article ID 1957612, 7 pages http://dx.doi.org/10.1155/2016/1957612

44. Wakelin S, Warren R, Kong L, Harvey P, 2008. Management factors affecting size and structure of soil Fusarium communities under irrigated maize in Australia. Appl Soil Ecol 39: 201-209

45. Wiese, M. V.(1987): Compendium of Wheat Diseases. 2nd edn. American Phytopathological Society Press,St. Paul, MN, USA.

\section{Figures}




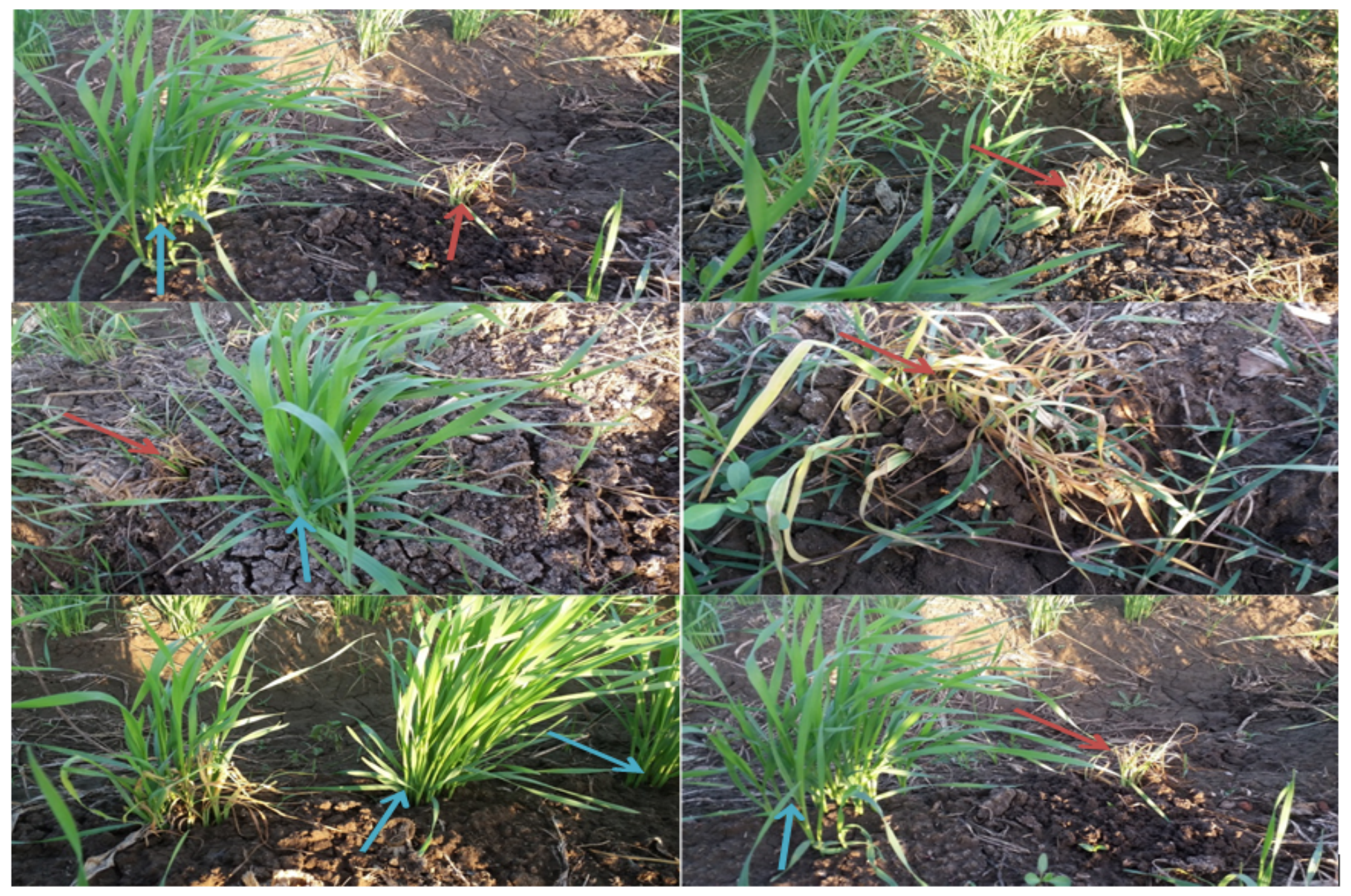

\section{Figure 1}

Isolation of wheat wilt accompanying fungi. Red arrows showing plant wilt symptoms, Blue arrows health plant. 


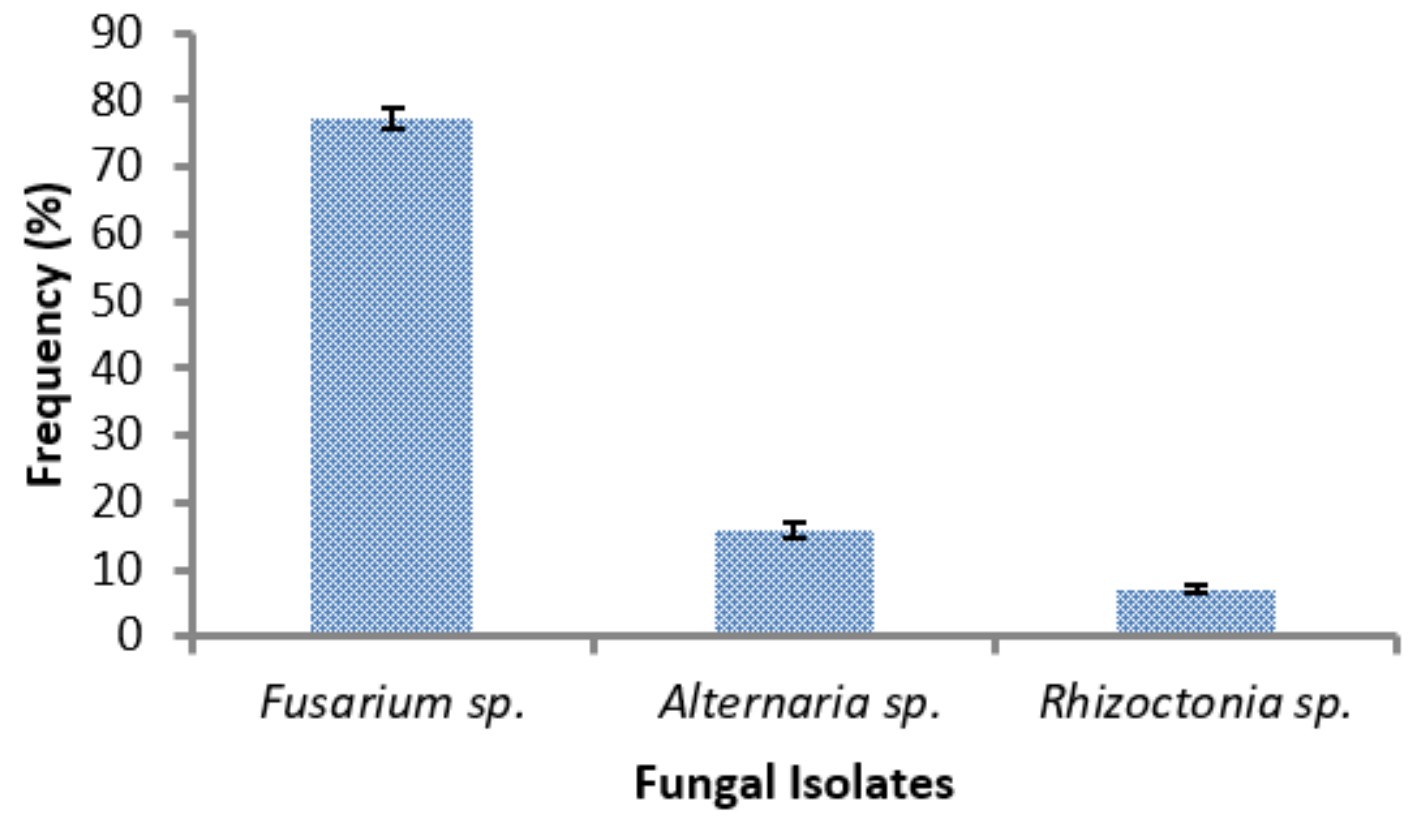

Figure 2

Frequency (\%) of fungal isolates

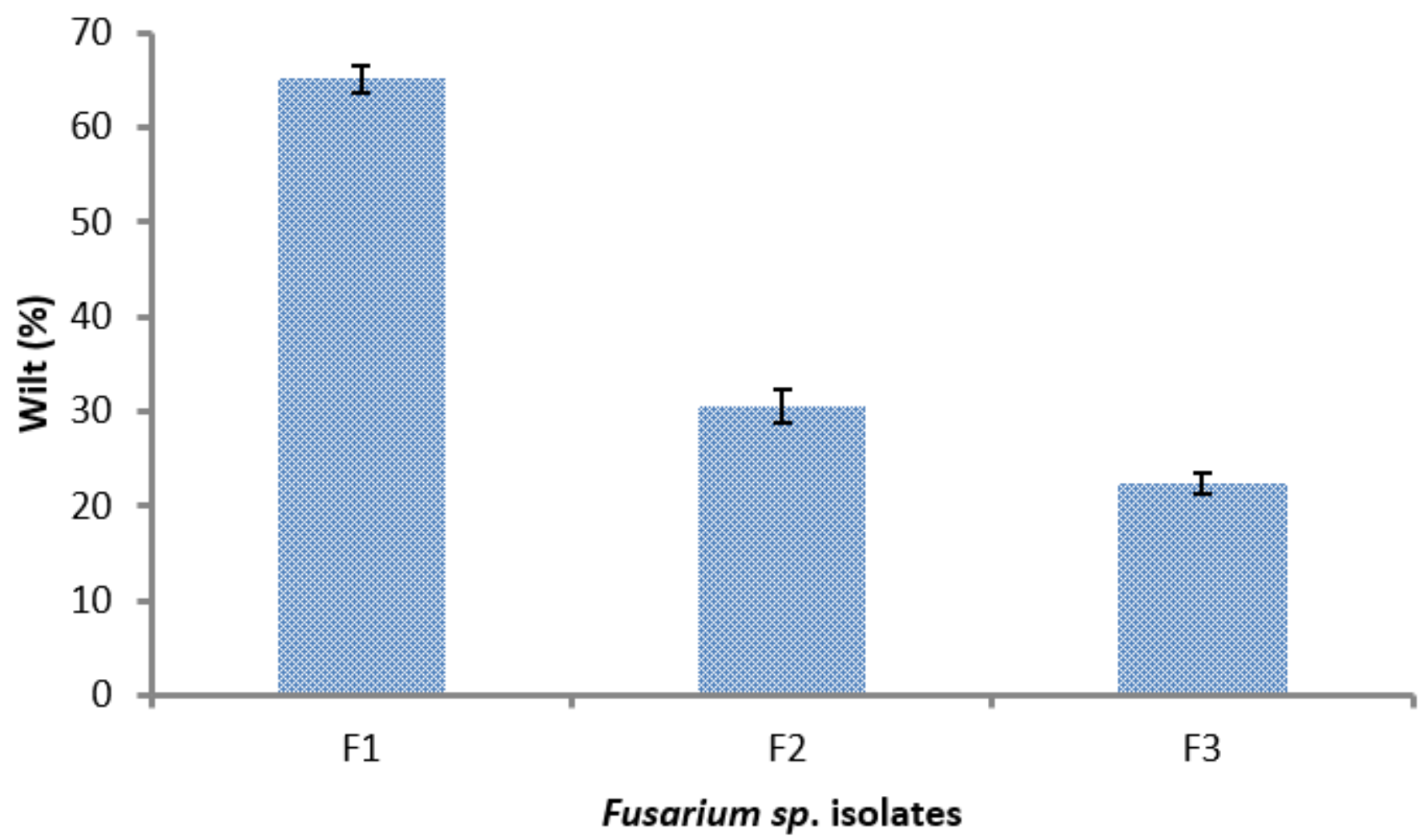

Figure 3

Wilt (\%) of wheat infected by Fusarium sp. isolates 


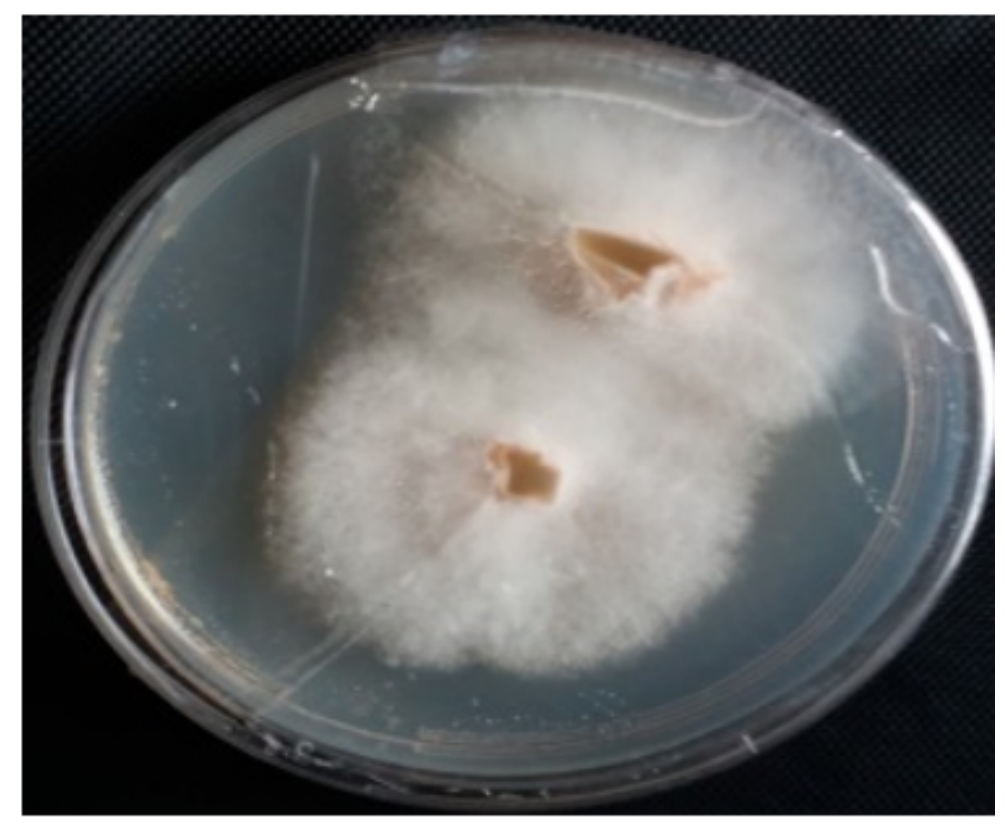

Figure 4

Colony of F. equiseti on Petri dish containing PDA 


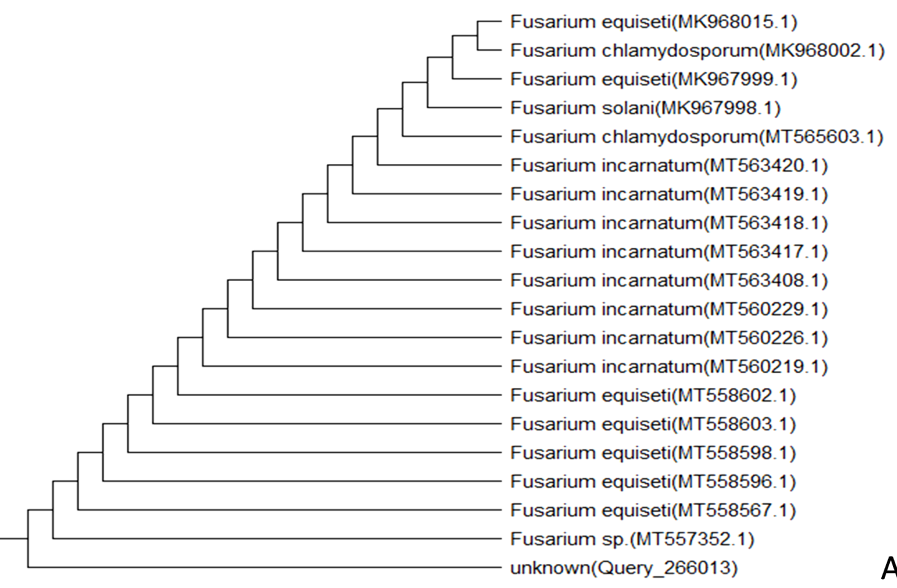

\begin{tabular}{|c|c|c|c|c|c|c|}
\hline Description & $\begin{array}{l}\text { Max } \\
\text { Score }\end{array}$ & $\begin{array}{l}\text { Total } \\
\text { Score }\end{array}$ & $\begin{array}{l}\text { Query } \\
\text { Cover }\end{array}$ & $\underset{\text { value }}{E}$ & $\begin{array}{l}\text { Per. } \\
\text { Ident }\end{array}$ & Accession \\
\hline iseni isolate SKASS BRH16F1 intermal transcribed spacer 1 , partial sequence, $58 \mathrm{~S}$ ribosomal RNA gene and intemal transcribed saacer 2 & 833 & 833 & $100 \%$ & 0.0 & $100.00 \%$ & $\underline{\mathrm{MK} 968015,1}$ \\
\hline bed spacer 1. partial sequence: $5.8 \mathrm{~S}$ ribosomal RNA gene and intermal transcribed & 833 & 833 & $100 \%$ & 0.0 & $100.00 \%$ & MK968002.1 \\
\hline 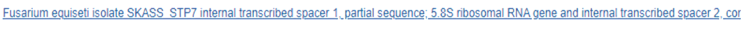 & 833 & 833 & $100 \%$ & 0.0 & $100.00 \%$ & MK967999.1 \\
\hline 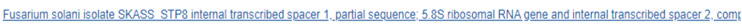 & 833 & 833 & $100 \%$ & 0.0 & $100.00 \%$ & MK967998.1 \\
\hline 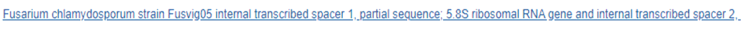 & 833 & 833 & $100 \%$ & 0.0 & $100.00 \%$ & $\underline{\text { MT5656031 }}$ \\
\hline 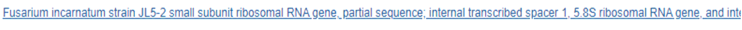 & 833 & 833 & $100 \%$ & 0.0 & $100.00 \%$ & MT563420.1 \\
\hline 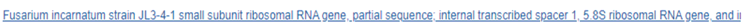 & 833 & 833 & $100 \%$ & 0.0 & $100.00 \%$ & MT563419.1 \\
\hline Fusarrium incarnatum strain CBB-2 Small subunit ribosomal RNA gene. vartial sequence: intermal transcribed spacer $1.58 \mathrm{~S}$ nbosomal RNA gene. and in & 833 & 833 & $100 \%$ & 0.0 & $100.00 \%$ & MT5634181 \\
\hline 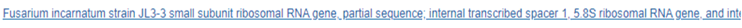 & 833 & 833 & $100 \%$ & 0.0 & $100.00 \%$ & MT563417.1 \\
\hline Fusarium incarnatum strain CBA-3 small subunit ribosomal RNA gene. jartial sequence: intemal trans scribed spacer $1.58 \mathrm{~S}$ nbososomal RNA gene. and in & & 833 & $100 \%$ & 0.0 & $100.00 \%$ & MT563408.1 \\
\hline 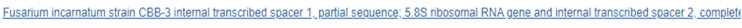 & 833 & 833 & $100 \%$ & 0.0 & $100.00 \%$ & MT5602291 \\
\hline 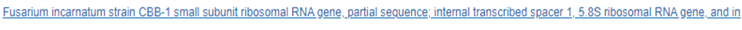 & 833 & 833 & $100 \%$ & 0.0 & $100.00 \%$ & MT560226.1 \\
\hline 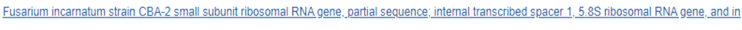 & 833 & 833 & $100 \%$ & 0.0 & $100.00 \%$ & MT560219.1 \\
\hline Fusarium equisei istrain CB33-2 small subunit ribosomal RNA gene, partial sequence: internal transcribed spacer $1.58 \mathrm{~S}$ ribosomal RNA gene, and inter & 833 & 833 & $100 \%$ & 0.0 & $100.00 \%$ & $\underline{\text { MT5586021 }}$ \\
\hline 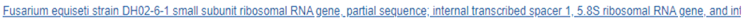 & 833 & 833 & $100 \%$ & 0.0 & $100.00 \%$ & MT5586031 \\
\hline 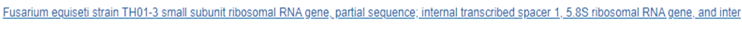 & 833 & 833 & $100 \%$ & 0.0 & $100.00 \%$ & MT5585981 \\
\hline ribosomal RNA gene, and inter & 833 & 833 & $100 \%$ & 0.0 & $100.00 \%$ & MT5585960.1 \\
\hline mequised strain DH02-6 small subunit ribosomal RNA gene. vartrial sequence, in & 833 & 833 & $100 \%$ & 0.0 & $100.00 \%$ & MT558567.1 \\
\hline usarium Sp i isolate RL521 intermal transcribed spacer 1 .partial sequence: $588 \mathrm{~S}$ ribosomal $R$ & & 833 & $100 \%$ & 0.0 & 100.00 & \\
\hline
\end{tabular}

\begin{tabular}{|c|c|c|c|}
\hline Query & 1 & GGAGGGATCATTACCGAGTTTACAACTCCCAAACCCCTGTGAACATACCTATACGTTGCC & 60 \\
\hline & & 11111111111111111111111111111111111111111111111111111111111 & \\
\hline Sbjet & 19 & GGAGGGATCATTACCGAGTTTACAACTCCCAAACCCCTGTGAACATACCTATACGTTGCC & 78 \\
\hline Query & 61 & TCGGCGGATCAGCCCGCGCCCCGTAAAACGGGACGGCCCGCCCGAGGACCCCTAAACTCT & 120 \\
\hline & & 111111111111111111111111111111111111111111111111111111111 & \\
\hline Sbjet & 79 & TCGGCGGATCAGCCCGCGCCCCGTAAAACGGGACGGCCCGCCCGAGGACCCCTAAACTCT & 138 \\
\hline Query & 121 & GTTTTTAGTGGAACTTCTGAGTAAAACAAACAAATAAATCAAAACTTTCAACAACGGATC & 180 \\
\hline & 11 & 111111111111111111111111111111111111111111111111111111111 & \\
\hline Sbjet & 139 & GTTTTTAGTGGAACTTCTGAGTAAAACAAACAAATAAATCAAAACTTTCAACAACGGATC & 198 \\
\hline Query & 181 & TCTTGGTTCTGGCATCGATGAAGAACGCAGCAAAATGCGATAAGTAATGTGAATTGCAGA & 240 \\
\hline & & 111111111111111111111111111111111111111111111111111111111111 & \\
\hline Sbjet & 199 & TCTTGGTTCTGGCATCGATGAAGAACGCAGCAAAATGCGATAAGTAATGTGAATTGCAGA & 258 \\
\hline Query & 241 & ATTCAGTGAATCATCGAATCTTTGAACGCACATTGCGCCCGCCAGTATTCTGGCGGGCAT & 300 \\
\hline & & 11111111111111111111111111111111111111111111111111111111111111 & \\
\hline Sbjet & 259 & АTTCAGTGAATCATCGAATCTTTGAACGCACATTGCGCCCGCCAGTATTCTGGCGGGCAT & 318 \\
\hline Query & 301 & GССTGTTCGAGCGTCATTTCAACCCTCAAGCTCAGCTTGGTGTTGGGACTCGCGGTAACC & 360 \\
\hline & 11 & 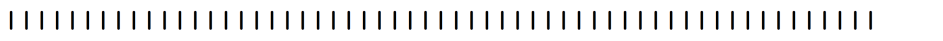 & \\
\hline Sbjet & 319 & GCCTGTTCGAGCGTCATTTCAACCCTCAAGCTCAGCTTGGTGTTGGGACTCGCGGTAACC & 378 \\
\hline Query & 361 & CGCGTTCCCCAAATCGATTGGCGGTCACGTCGAGCTTCCATAGCGTAGTAATCATACACC & 420 \\
\hline & 11 & 1111111111111111111111111111111111111111111111111111111111 & \\
\hline Sbjct & 379 & CGCGTTCCCCAAATCGATTGGCGGTCACGTCGAGCTTCCATAGCGTAGTAATCATACACC & 438 \\
\hline Query & 421 & TCGTTACTGGTA 432 & \\
\hline & & 1111111111111 & \\
\hline Sbjet & 439 & TCGTTACTGGTA & \\
\hline
\end{tabular}

Figure 5

(A) Phylogenetic tree among the Fusarium equiseti strain SKASS_BRH16F1 and the ITS sequences of closely related fungal strains retrieved from the NCBI GenBank database; and (B)Cluster analysis of Fusarium equiseti 

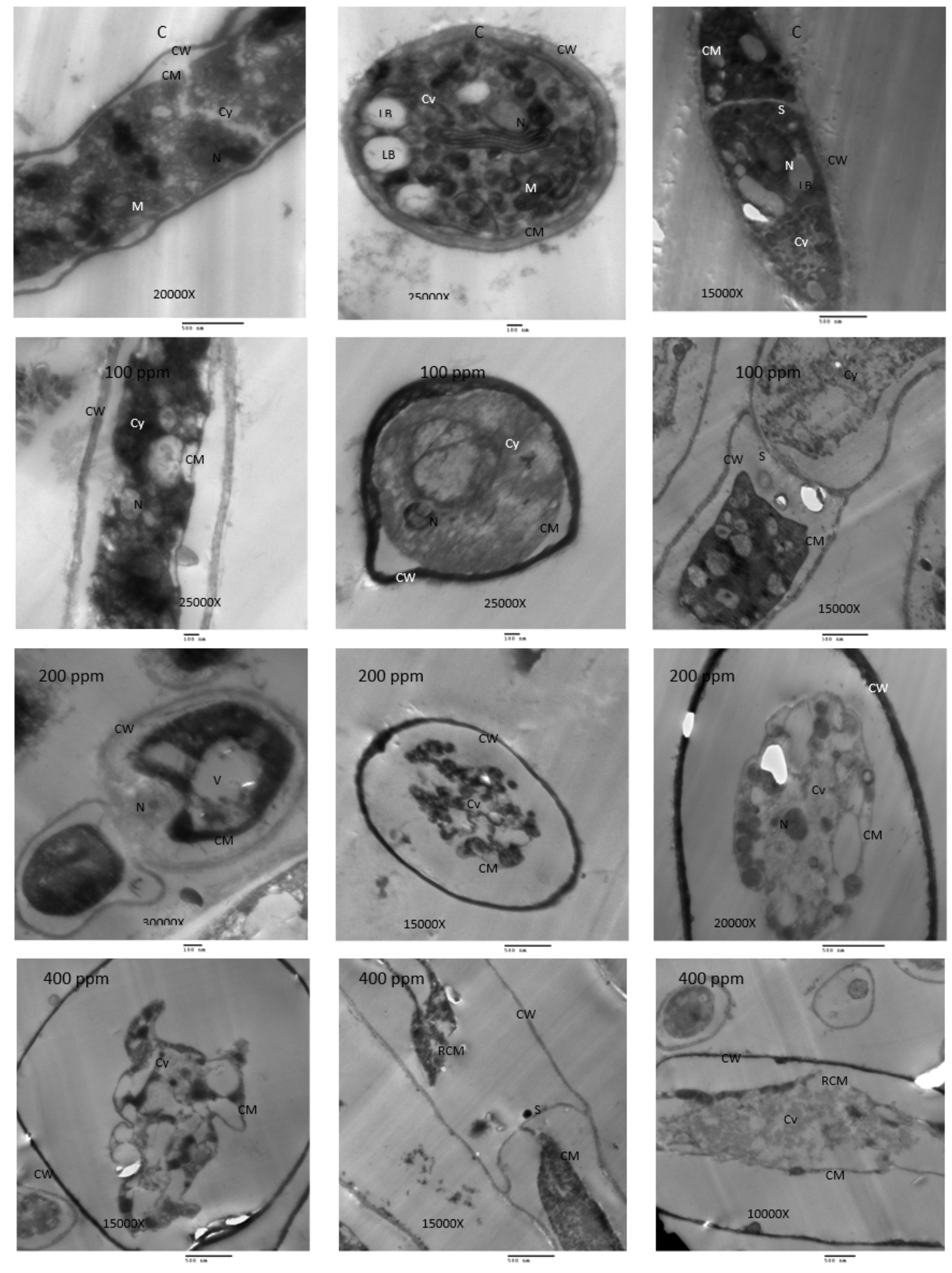

Figure 6

Ultrastructures of F. equiseti at different concentrations of CuONPs (100, 200 and 400ppm)

\section{Supplementary Files}

This is a list of supplementary files associated with this preprint. Click to download. 
- Graphical.docx

Page 21/21 